\title{
The xenotropic microRNA gene information for stem cell researches and clinical applications
}

\author{
Yoichi Robertus Fujii \\ Retroviral Genetics Group, Nagoya City University, Nagoya, Japan; fatfuji@hotmail.co.jp
}

Received 9 November 2012; revised 8 December 2012; accepted 2 January 2013

\begin{abstract}
MicorRNA (miRNA) is a small noncoding RNA and a miRNA is the gene. The identification of the human miRNA gene and its application have been performed and then it has been proceeding to explain about functioning of miRNAs in miRNA-messenger RNA targeting, profiling of miRNAs for diseases, transduction of the miRNA gene expression, production of human-induced pluripotent stem (iPS) cells by miRNA, embryonic stem (ES) cells and cancer development upon miRNA. The RNA information supplied by the miRNA gene, and the RNA gene information could expand to intracellular, intercellular, intraorgan, interorgan, intraspecies and interspecies. Therefore, the implantation of ES and iPS cells from donors would deliver xenotropic miRNAs to the acceptor. The therapeutic efficacy for treatment of iPS-derived cell implantation is the most important for clinical development of the stem cell researches but the xenotropic miRNA gene assessment with iPS-derived cells should substantially be completed for a safe and an exact application of the stem cell researches.
\end{abstract}

Keywords: ES Cell; Evolution; iPS Cells; Implantation; MicroRNA; Retroelement; RNA Wave; Xentropism

\section{INTRODUCTION}

MicroRNAs (miRNAs) are the dominance of small endogenous RNA, 17 - 31 nucleotides (nts) length in humans and the miRNA genes are produced from non-coding regions and coding regions containing the introns or exons in the human genome [1,2]. These endogenous small RNAs are functional and inhibit or augment transcription and posttranscription [2-4]. Therefore, most of all protein expression can be fine-tuned and subsequently our life is controlled by the miRNA genes. It has been reported by Lin and Ying [5] that 2012 year's Nobel prize subject, "induced pluripotent stem (iPS) cells" were well induced with the miRNA genes. The miRNA profiles of the stem cells have been shown that expression of miRNAs is induced according to the lineage specific form stem cells [6,7]. Further, the miRNA is the mobile genetic element and the exosomal miRNAs can be released from the donor $[8,9]$. The donor miRNAs are incorporated into the acceptor cells and the miRNA can regulate the acceptor protein expression $[10,11]$. In the case of the oncomir, its miRNA could have tumorigenic abilites against an acceptor cell [12-14]. When the control of the experimental stem cell is investigated and further implantation of the stem cells is developed, stem cell researchers have to face up to the xenotropic miRNA genes. The new problematic issues by the xenotropic miRNAs are explained in this document.

\section{MIRNA GENOTYPES}

\subsection{The Genomic and Resident miRNA Genes in a Stem Cell}

miRNA is a small noncoding RNA and a miRNA is the gene, therefore, most of all human diseases would be the genetic disease because of its function as the master regulator of protein gene expression including transcripttional factor proteins and histone remodeling regulating enzymes, which are related with the epigene. The miRNA gene has two genetic types, one is the genomic miRNA gene and the other is the resident miRNA gene which have been hypothesized in RNA Wave model, which would construct "somatic genome variations" (Figure 1) $[15,16]$. The resident microRNA gene expression is altered by the environmental effects, that contain tempruture, X-ray, foods, chemical carcinogens, exercises, medicine and transduction with the protein genes, such as in iPS cells. As shown in Figure 1, ES cells show the resident miRNA profile of A and after miR-1 induction, differentiated cardiac myocyte $\mathrm{P}$ would show that of $\mathrm{B}$. In this case, genotype of DNA in the genome is likely to be the same (same colored). Using the human stem cells in an experiment, we can compared with the data among 
miRNA profile $\mathrm{A}$

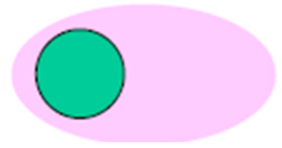

ES cell

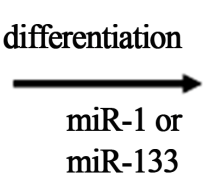

miR-133

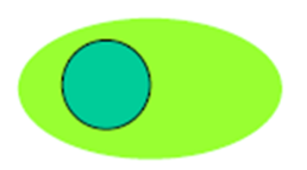

miRNA profile B

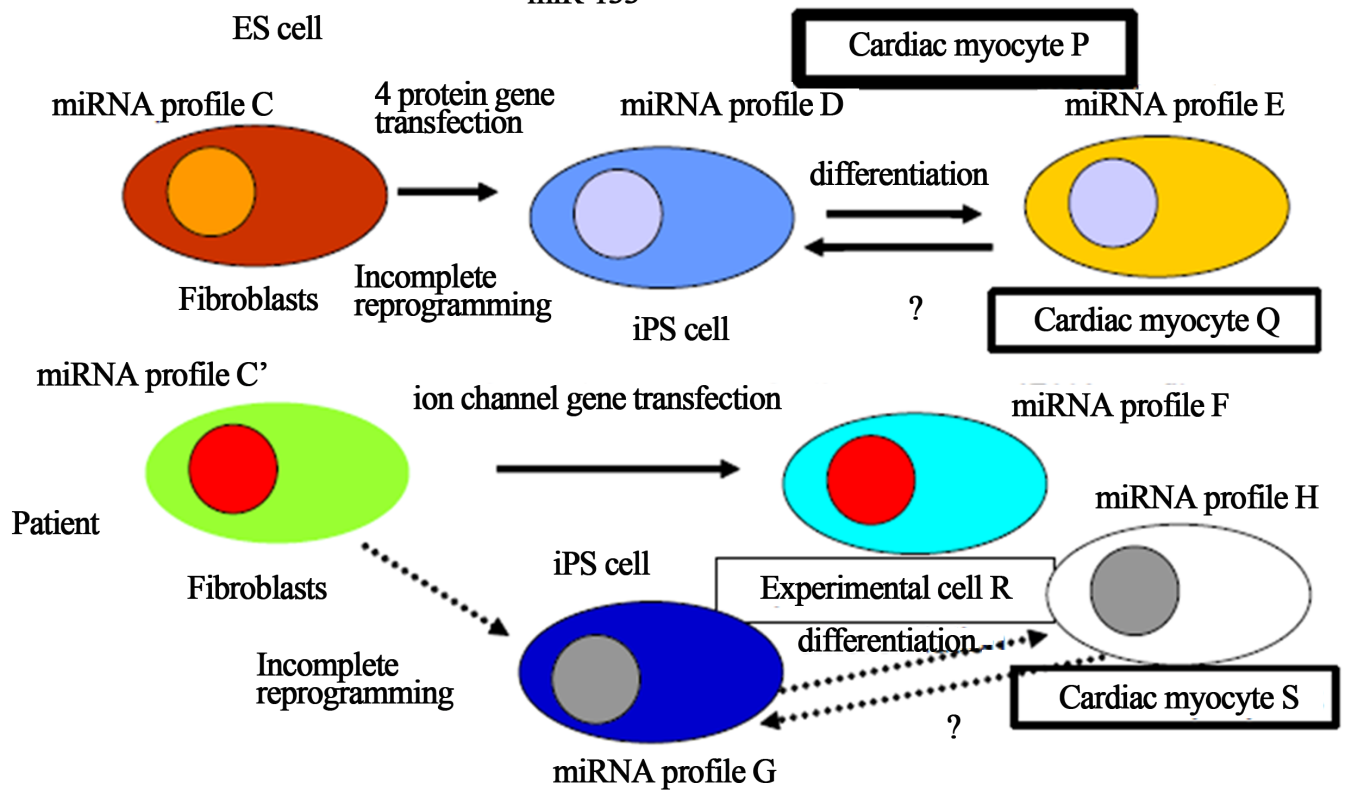

Figure 1. Xenotropic miRNA genes derived from iPS cells. The genomic miRNA gene profile and the resident miRNA profile were represented in the case of ES cells, iPS cells of healthy donor and iPS cells from patient. Different colored cytosol and nucleus show different genotype profile of miRNAs. These colors can move to niches and the miRNAs of niches can also transfer to implanted iPS-derived cells, such as cardiac myocytes, it is corresponding that the miRNA genes are mobile genetic elements. It has not yet been reported whether after implantation, differentiated iPS cells from healthy donor are reversed to iPS miRNA genotype or are super-differentiated to cardiac myocyte's aberrant miRNA genotype of patient into the acceptor patient cells.

original, ES cell-derived and disease model mouse myocytes for the experiments. iPS cells, however, from fibroblasts to cardiac myocyte $\mathrm{Q}$, the resident miRNA profiles show, at least three resident miRNA gene profiles (C, D and $\mathrm{E}$ ). About the epigenetic state, since iPS cells were increasing retroelement expression from the genome [17], the genomic miRNA gene would be altered. Eventhough inbred strain mice were used for an experiment, similar problems of difference in genetic backgrounds of the miRNA genes would be born. Further, patient's fibriblasts also have three resident genotypes (C', G and $\mathrm{H}$ ) during reprogramming and diferentiation (cardiac myocyte S), and ion channel gene-transfected cells have the profile of $\mathrm{F}$ (experimental cell $\mathrm{R}$ ).

\section{2. miRNAs for Renewal and Differentiation of the Stem Cell}

Since it has been reported that miR-302 cluster and miR-367 directly reprogrammed murine and human somatic cells without other additional factors and requirement of vector-based gene therapy [18,19], it might offer a safe approach for iPS reprogramming. Although the profile of miR-17-92, miR-106a-363, miR-302-367, and miR-200 clusters showed a similar expression between ES and iPS cells, Sharma and Wu have reported that the expression pattern including other miRNA is not same at all [6]. Further, tumor suppressor miR-305 may provide to prevent tumorigenecity upon iPS cell reprogramming [5], however, amount of miR-305 expression in iPS cells is not controlled corresponding to that of it in ES cells. Therefore, the small difference of the resident genotype is likely to grow larger difference of miRNA profiles in the developed cells. Subsequently, when four resident miRNA genotype cells as well as epigenomic different cells were obtained (P, Q, R and S) from four origins, the four differentiated cells would have different functions (Figure 1). For example, miR-1 tuned cardiac progenitor cells and myoblast proliferation but miR-499 is implicated in differentiation of c-kit+ cardiac stem cells, suggesting that a different miRNA profile shows different cell functions, therefore, 4 resident miRNA genotype expressing cardiac myocytes may have different myocyte functions [20]. Although each resident miRNA gene plays 
a crucial role in ES cell renewal and differentiation, its tuning pattern of genes are contributed to the lineage of cardiac myocytes.

\section{XENOTROPIC MIRNA GENE}

\subsection{The Exosomal miRNA Genes from Stem Cells and Niches}

Here is the serious issue for clinical application of iPS cells induced by transcription factors that even if HLA fitted donor and acceptor but the resident miRNA genotype is different. Further, if iPS reprogramming is not complete one, implanted iPS derived myocardiac cells could be affected by exosomal moving miRNA genes in niches and we do not know whether iPS myocytes would be reversed to iPS cells before differentiation or not, because ES and iPS cells were reversed to the 2C stage-like cells increasing passage [21]. Furthermore, the accepotor has some possibility that when the patient as an acceptor has genetic disorder, aberrant genoimc miRNA genes were expressed in the acceptor cells and those miRNAs can transfer to implanted iPS myocytes in situ and the iPS myocytes may be reversed to patient cardiac cells or aberration of miRNAs may induce cardiac diseases, such as hypertrophy again. In turn, xenotorpic retroelements as well as xenotropic resident miRNA genes from the donor iPS cells may have some influence to acceptor homeostasis by miRNA gene fine-tuning and differentiated iPS cells from healthy donor are reversed to original iPS miRNA genotype or are super-differentiated to cardiac myocyte's aberrant miRNA genotype of patient into the acceptor patient cells. Again, miRNA is the gene; xenotropic resident miRNA, therefore, can be converted to genomic miRNA and integrated into the genomic DNA of the acceptor germ line. Since the acquired genotype including epigenes could be inherited from iPS acceptor to the child, we should more deeply consider the influence of xenotropic miRNAs in the offsprings of iPS cellimplanted parent according to the profiles of donor resident miRNAs and acceptor genomic miRNAs during several generations.

\subsection{A Resemblance between the Xenotropic miRNA and the Food-Derived miRNA}

Further, as concerning to the xenotropic miRNA genes, iPS implantation has the same problem as genetically modified organism (GMO) plant [22] because it is yet known that plant miRNAs can survive cooking and digestion and enter in animal sera and tissues, and the uptaken palnt miRNA genes can regulate animal gene expression [23-25]. If the xenotropic GMO plant miRNA has the ability of oncomir in human, the mammalian cells would be induced upon tumorigenic gene expres- sion by the xenotropic miRNAs [22]. Recently, nanoparticles, such as orally applicable poly-lactide-co-glycolide (PLGA, $<500 \mathrm{~nm}$ ), which is approved by the Food and Drug Administration (FDA) in the United States [26] have been used as a vehicle for pharmaceutical delivery of the RNA genes to treat colorectal tumor in nude mice [27]. The result is a clear evidence that the xenotropic RNA information of food could have an affect on the regulation of miRNAs in the acceptor cells and suggest that the xenotropic miRNA may be useful for application of anti-cancer research. Of course, it is not yet known whether the plant miRNA can be toxic for human cells, however, in the case of implantation of human iPS or ESderived cells, it is well known that the human cells express both oncomirs and tumor suppressor miRNAs [28]. For the all the evidence and speculation to the contrary, if the roadmap for the clinical trial be set up with iPS-derived cells or organs, before that, not only the therapeutic efficacy for treatment of iPS-derived cell implantation but also xenotropic miRNA gene assessment with iPSderived cells should be completed for a safe gateway.

\section{CONCLUSION}

\section{Inheritable Xenotropic miRNA Gene Information}

miRNA is the gene. The new problematic issues of therapy with stem cells present in recognition of the genetics. Given the language of miRNA gene information, "evolution" with mutations and recombinations may be at least, in part, operated in its programmed orders by the miRNA genes including the xenotropic miRNAs. Therefore, the evolution might have been programmed by the xenotropic miRNA information. It is named as the programmed evolution. Diseases are deeply associated with disorder of miRNA expression in cells. In turn, abnormal xenotropic miRNA induces system errors. While the miRNA gene would be originally derived from retrotransposon, miRNA can be mobile in the every space according to the RNA Wave model. Therefore, the spontaneous mutation and recombination with the xenotropic miRNAs would also induce information errors and that can also cause human diseases. The inheritable phenotypes may be readily programmed in the miRNA gene information written with the miRNA algorithm and the acquired characters in Darwinism could transmit from one to another via the xenotropic miRNA. Therefore, the genetic disorders by the xenotropic miRNA would be inherited. Further, since the xenotropic miRNA might be related with the evolution, iPS implantation may be artificially involved in the co-evolution. We should assume full responsibility for aberrant evolution by xenotropic miRNAs under the stem cell implantation. 


\section{REFERENCES}

[1] Fujii, Y.R. (2010) RNA genes: Retroelements and virally retroposable microRNAs in human embryonic stem cells. The Open Virology Journal, 4, 63-75. doi:10.2174/1874357901004010063

[2] Lin, S.L. and Ying, S.Y. (2013) Gene silencing in vitro and in vivo using intronic microRNAs. Methods in Molecular Biology, 936, 209-229.

[3] Khraiwesh, B., Arif, M.A., Seumel, G.I., Ossowski, S., Weigel, D., Reski, R. and Frank, W. (2009) Transcriptional control of gene expression by microRNAs. Cell, 140, 111-122. doi:10.1016/j.cell.2009.12.023

[4] Raver-Shapira, N., Marciano, E., Meiri, E., Spector, Y., Rosenfeld, N., Moskovits, N., Benhwich, Z. and Oren, M. (2007) Transcriptional activation of miR-34a contributes to p53-mediated apoptosis. Molecular Cell, 26, 731-743. doi:10.1016/j.molcel.2007.05.017

[5] Lin, S.-L. and Ying, S.-Y. (2013) Mechanism and Method for generating tumor-free iPS cells using intronic micro RNA miR-302 induction. In: Ying, S.-Y., Ed., MicroRNA Protocols. 2nd Edition, Humana Press, Springer, New York, 295-312.

[6] Sharma, A. and Wu, J.C. (2013) MicroRNA expression profiling of human-induced pluripotent and embryonic stew cells. In: Ying, S.-Y., Ed., MicroRNA Protocols. 2nd Edition, Humana Press, Springer, New York, 247-256. doi:10.1007/978-1-62703-083-0_19

[7] Wang, J. and Yang, X. (2012) The function of miRNA in cardiac hypertrophy. Cellular Molecular Life Science, 69, 3561-3570. doi:10.1007/s00018-012-1126-y

[8] Wang, K., Zhang, S., Marzolf, B., Troisch, P., Brightman, A., Hu, Z., Hood, L.E. and Galas, D.J. (2009) Circulating microRNAs, potential biomarkers for drug-induced liver injury. Proceedings of the National Academy of Sciences, 106, 4402-4407. doi:10.1073/pnas.0813371106

[9] Turchinovich, A., Weiz, L., Langheinz, A. and Burwinkel, B. (2011) Characterization of extracellular circulating microRNA. Nucleic Acids Research, 39, 7223-7233. doi:10.1093/nar/gkr254

[10] Vickers, K.C., Palmisano, B.T., Shoucri, B.M., Shamburek, R.D. and Remaley, A.T. (2011) MicroRNAs are transported in plasma and delivered to recipient cells by high-density lipoproteins. Nature Cell Biology, 13, 423435. doi:10.1038/ncb2210

[11] Gibbings, D.J., Ciaudo, C., Erhardt, M. and Voinnet, O. (2009) Multivesicular bodies associate with components of miRNA effector complexes and modulate miRNA activity. Nature Cell Biology, 11, 1143-1151.

[12] Wang, X., Tang, S., Le, S.Y., Lu, R., Rader, J.S., Meyer, C. and Zheng, Z.-M. (2008) Aberrant expression of oncogenic and tumor-suppressive microRNAs in cervical cancer is required for cancer cell growth. PLoS One, 3, e2557.

[13] Wang, X., Wang, H.-K., Mccoy, J.P., Banerjee, N.S., Rader, J.S., Broker, T.R., Meyers, C., Chow, L.T. and Zheng, Z.-M. (2009) Oncogenic HPV infection interrupts the expression of tumor-suppressive miR-34a through viral on- coprotein E6. RNA, 15, 637-647. doi:10.1261/rna.1442309

[14] Meckes Jr., D.G., Shair, K.H.Y., Marquitz, A.R., Kung, C.-P., Edwards, R.H. and Raab-Traub, N. (2010) Human tumor virus utilizes exosomes for intercellular communication. Proceedings of the National Academy of Sciences, 107, 20370-20375. doi:10.1073/pnas.1014194107

[15] Fujii, Y.R. (2008) Fromulation of new algorithmics for mi RNAs. The Open Virology Journal, 2, 37-43. doi:10.2174/1874357900802010037

[16] Astolfi, P.A., Salamini, F. and Sgaramella, V. (2010) Are we genomic mosaics? Variations of the genome of somatic cells can contribute to diversity our phenotypes. Current Genomics, 11, 379-386. doi:10.2174/138920210793175949

[17] Wissing, S., Muoñz-Lopez, M., Macia, A., Yang, Z., Montano, M., Collins, W., Garcia-Perez, J.L., Moran, J.V. and Greene. W.C. (2012) Reprogramming somatic cells into iPS cells activates LINE-1 retroelement mobility. Human Molecular Genetics, 21, 208-218. doi:10.1093/hmg/ddr455

[18] Lin, S.L., Chang, D.C., Chang-Lin, S., Lin, C.H., Wu, D.T., Chen, D.T. and Ying, S.Y. (2008) Mir-302 reprograms human skin cancer cells into a pluripotent ES-celllike state. RNA, 14, 2115-2124. doi:10.1261/rna.1162708

[19] Anokye-Danso, F., Trivedi, C.M., Juhr, D., Gupta, M., Cui, Z., Tian, Y., Zhang, Y. Yang, W., Gruber, P.J., Epstein, J.A. and Morrisey, E.E. (2011) Highly efficient miRNAmediated reprogramming of mouse and human somatic cells to pluripotency. Cell Stem Cell, 8, 376-388. doi:10.1016/j.stem.2011.03.001

[20] Wang, J. and Yang, X. (2012) The function of miRNA in cardiac hypertrophy. Cellular Molecular Life Sciences, 69, 3561-3570. doi:10.1007/s00018-012-1126-y

[21] Macfarlan, T.S., Gifford, W.D., Driscoll, S., Lettier, K., Rowe, H.M., Bonanomi, D., Firth, A., Singer, O., Trono, D. and Pfaff, S.L. (2012) Embryonic stem cell potency fluctuates with endogenous retrovirus activity. Nature, 487, 57-65. doi:10.1038/nature11244

[22] Séralini, G.E., Clair, E., Mesnage, R., Gress, S., Defarge, N., Malatesta, M., Hennequin, D. and de Vendômois, J.S. (2012) Long term toxicity of a roundup herbicide and a roundup-tolerant generally modified maize. Food Chemical Toxicology, 50, 4221-4231. doi:10.1016/j.fct.2012.08.005

[23] Chrupek, M., Siipi, H. and Martinelli, L. (2012) Bio-objects as "boundary crawlers": The case of microRNA. Croat Medical Journal, 53, 285-288. doi:10.3325/cmj.2012.53.285

[24] Jiang, M., Sang, X. and Horg, Z. (2012) Beyond nutrients: Food-derived microRNAs provide cross-kingdom regulation. Bioassays, 34, 280-284. doi:10.1002/bies.201100181

[25] Zhang, L., Hou, D., Chen, X., Donghai, L., Zhu, L., Zhang, L., Li, J., Bian, Z., Liang, X., Cai, X., Yin, Y., Wang, C., Zhang, T., Zhu, D., Zhang, D., Xu, J., Chen, Q., Ba, Y., Liu, J., Wang, Q., Chen, J., Wang, J. Wang, M., Zhang, Q., Zhang, J., Zen, K. and Zhang, C.-Y. (2012) Exogenous plant MIR168a specifically targets mammal- 
ian LDLRAP1: evidence of cross-kingdom regulation by microRNA. Cell Research, 22, 207-126.

doi:10.1038/cr.2011.158

[26] Garinot, M., Fievenz, V., Pourcelle, V., Stoffelbach, F., des Rieux, A., Plapied, L., Theate, I., Freichels, H., Jerome, C., Marchand-Brynaert, J., Schneider, Y.J. and Préat, V. (2007) PEGylated PLGA-based nanoparticles targeting M cells for oral vaccination. Journal of Controlled Release, 120, 195-204.

doi:10.1016/j.jconrel.2007.04.021
[27] Sureban, S.M., May, R., Mondalek, F.G., Qu, D., Ponnurangam, S., Pantazis, P., Anant, S., Ramanujam, R.P. and Houchen, C.W. (2011) Nanoparticle-based delivery of siDCAMKL-1 increases microRNA-144 and inhibits colorectal cancer tumor growth via a Notch-1 dependent mechanism. Journal of Nanobiotechnology, 9, 40. doi:10.1186/1477-3155-9-40

[28] Fujii, Y.R. (2009) Oncoviruses and pathogenic microRNAs in humans. The Open Virology Journal, 3, 37-51. 